\title{
Reading the Subtitles and Captions in Dances With Wolves
}

\author{
By Hildi \& Paul Tiessen \\ Spring 1994 Issue of KINEMA
}

DANCES WITH WOLVES INVITES THE VIEWER into the inner and outer worlds of Lt. Dunbar, alias Kevin Costner, alias Dances With Wolves. The audio-visual text of this film -- which ends with the "spine-tingling howl" of a wolf framed by a "great, yellow full moon" and, then, Dances With Wolves and Stands With A Fist (played by Mary McDonnell) walking together up a canyon trail, away from the camera which "slowly pulls back" -- precedes the coda-like pronouncement of the closing caption: "Thirteen years later, their homes destroyed, their buffalo gone, the last band of free Sioux submitted to white authority at Fort Robinson, Nebraska. The great horse culture of the plain was gone and the American Frontier was about to pass into history."(1) The epic-length text of Dances With Wolves invites the viewer to identify totally and unabashedly with the almost absurdly heroic and deliciously vulnerable child/man who is the film's questing protagonist, its knight-errant. And reviewers have tended to see the film as marking a cinematic emancipation of native North Americans, as signalling an opportunity for the individual- and mass-mind to resist the stereotypical imprinting apparatus of institutionalized images of North American natives. But should we so uncritically enter the obviously appealing construction of Dunbar's life and, through Dunbar, the movie as a whole -- or should we exert a certain caution?

What a life (however saccharinely put) we are given to enter! From our pleasure and relief at his manic slicing through and against the deadly malaise, the bureaucratized paralysis, of civilized officialdom during the military stalemate of the opening sequences, to our expanding joy at his freeing himself from an overstuffed institutionalism when he releases himself in stages to the purity of a wilderness only a little tainted (as in the polluted waste of an abandoned military outpost) and not yet overcome by the heedless "progress" of civilization, we applaud our own fluid and easy entry into Dunbar's psychic universe. We, too, we come to feel, want to get away from the over-complicated lethargy of an urbanizing, industrializing, militarizing technological world, and pilgrimage as he pilgrimages toward an uncluttered, purified humanness. We - especially any contemporary middle-class viewer hectored by fears of ecological and innumerable other breakdowns in our physical and cultural, personal and social, post-Christian environments -- quite willingly slide into the emotionality and spirituality of the soft ambient space opened for us by Dunbar's quest. We, if we come from the dominant, middle-class, white-man's audience, respond readily to Dunbar/Costner's opening display of desperate heroism and rugged individualism, later to his wide-eyed cheeriness, little-boy naivete, and budding poetic sensibility, his well-scrubbed and domesticated orderliness, his determined and friendly school-boy charm and humanness, his seemingly untutored impulsiveness (even impetuousness) and spontaneity of body and mind and spirit, his generosity of heart and hand. So warmly wooed, so assuringly massaged, is the audience by the depth and breadth of the warm path of politically-correct gestures and overtures by the Lt. Dunbar character, that whatever its anxieties about its changing place among the ethnic and racial groups of North America, it comes to believe (500 years after Columbus) that it occupies a place of historical innocence, in effect, a special child/man's place, a place not occupied by those other "whites" depicted in that movie. ${ }^{(2)}$

Does the wash of soul-warming techniques imbedded in the essentially mythic narrative of Dunbar's pilgrimage into the heart of his purest self ultimately dominate the currents of the movie so fully that our conscience, and perhaps even our consciousness, is released even from the grip of the film's last word, its post-script, its closing caption? In its description of the later fate of the Lakota Sioux, that caption acts as a stern admonishment and seems for a moment to usurp the audio-visual text's final position by offering its own word as the film's last word. It makes a point of at least pretending to draw viewers beyond the cleansing wash, the blythe baptism into innocence, offered by the film as a whole. But is the closing caption really part of another story, another film?

Dances With Wolves, released in November, 1990, met with enormous public approval in the western world, not simply as entertainment, but as a relatively progressive Hollywood-made, revisionist Western that seemed to engage in enlightened socio-political gestures: this old-fashioned but environmentally aware frontier movie 
not only portrays an uplifting "New Age" spirituality through its gentle, white-male protagonist, but also portrays native Americans in a way that tries to suggest a real and symbolic breakthrough by giving them a voice. It is interesting to observe that it gives native Americans not just a voice that can be heard in an extended and complex way, but a voice that -- in the film's English-language-translation sub-titles -- can be seen, can be read. That is, by means of a print format familiar to us through our practice of reading the sub-titles of non-English films of international auteurs, Dances With Wolves confers cultural meaning upon -- and gives a heightened status to -- the native voice. The subtleties of warmth, humour, passion, weakness, fear, strength, conviction, wisdom -- all these and other qualities and dimensions of character seem to be respectfully and authoritatively conveyed by the subtitled transcription of the Lakota voice.

In its use of sub-titles, the film, already embracing its audience's emotional field so warmly, seems to acknowledge the audience's intellect with a distinctly respectful nod, too. Here and there, in the very gaps that flicker between the visual/auditory text that we see/hear and the printed text that we read, we recognize our own humanness, as we knowingly and sympathetically register the comic ironies and misunderstandings that occur inevitably when diverse cultures meet. By noticing and filling in these gaps, we feel ourselves entering and participating in the wonder and the wisdom, the celebration of human fallibility and foibles, of the film. Our fleeting recognition of ironies and awkwardnesses makes us feel, for a time, intellectually "empowered." We become all the more active and engaged participants in a narrative that implies (as we have seen) a new and benign socio-cinematic world order.

Of course many viewers quickly recognize that there are dynamics operating within Dances With Wolves that quite obviously reflect not only its relatively progressive, but also its more conservative ideological biases. By so bluntly and aggressively structuring and determining the course of audience response in relation to its central film "star," Dances With Wolves leads its audience to realize that its passionate identity lies, in fact, outside of any socio-political criticism. That is, the film, through its combination of historically accurate signposts with its invitation to its audience to grow in at least some form of awareness, tries with some success to seduce the spectator into believing in his own growing political astuteness, while letting him find himself -- at the end of its audio-visual text -- revelling merely in the comfort of his own innocence, in an essentially "apolitical" feeling stemming from and buoyed up by the alluring beauty, the simplicity, of the deep reservoir of innocence found in the protagonist as he completes his quest or pilgrimage surrounded by natives with whom he has become as one.

Can this film somehow be conservative and progressive, reactionary and radical, at once, simultaneously offering a justification for the North American status quo and producing a call to address the imbalances of a society (or even the imbalances of a series of film conventions and genres and formulas, in which the native is systemically put upon, or kept politically silent)? Or do the apparently contrary pressures of the film give but brief and controlled life to a politicized audience, only to give way to larger pressures that anaesthetize that momentarily politicized audience and firmly lay it to rest?

At a few points in the film it seems as though a response to that last question might go either way. But any doubt about the political alignment of the constructed audience can be clarified by our concentrating now on the closing moments of Dances With Wolves; there we can further explore the fate of this film's audience.

The appearance of the caption printed at the end of Dances With Wolves invites viewers to consider the elaborate variations on narrative technique in this film. The caption operates on the film fairly dogmatically and categorically, offering a documenting and documentary form of closure to a work that makes a point throughout of announcing or conferring meaning through various other uses of the written word, including the sub-titles in translation, and the occasional historical signpost, as in the opening caption. What are the implications in this film of a final printed caption that on the one hand seems to extend and complete the sum of certain narrative strands of the movie, but on the other actually challenges and de-stabilizes our sense of the general authority of the preceding audio-visual material?

Certainly the closing caption re-states tersely the viewer's general knowledge about the fate of the last band of free Sioux, even though the 13 years between 1863, the year which the film depicts, and 1876, the year implicitly cited in the caption, pass without detailed comment. In this movie of so much purity of action and purity of longing, viewers, essentially encouraged to avoid applying to themselves the issues raised by the caption, might be fairly content to enter the pristine tabula rasa of the 13-year gap. Encouraged to find 
within themselves a reflection of Lt. Dunbar, viewers very well might be eager to let newly-formed narrative possibilities flood the beckoning shape of that 13-year durational void, to take their place as Dunbarian observers of (rather than implicated perpetrators of evil in) that abyss, that Conradian/Kurtzian horror of thirteen years of unwritten and unspoken history placed between the book-ends of a glossy, fictional story streaked with documentary techniques and a seemingly factual, historical closing statement.

Indeed, that a caption -- comprising "objective" words that would seem to signal their freedom from the possible unreliability of movie images, that would seem to signal their superiority over the profligate and unstable inconstancy of sounds in the film (noise, music, dialogue) -- should lay claim to a movie-goer's attention is conventional enough, grounded as it is in cinema's reliance (first during the silent era, and confirmed and even reinforced in the sound era) on the authority of the written word. A closing (as also an opening) caption might routinely have a kind of stabilizing effect on the narrative and thematic business of a movie; as a privileged last, or first, word it can determine in the written details of its packaging instructions a sense of a specific approach to or interpretation of a film.

In the case of Dances With Wolves, the closing caption actually does extend not only selected strata in the narrative of the movie but also, as we have suggested, some of the technical or formal elements already present in the construction of the film. This film has included sub-titles giving us a chance to read in written translation the words of an oral people; it has included the verbalized presentations of Lt. Dunbar's written chronicles so filled with a yearning for an innocent edenic state, indeed, chronicles mapping out his and our route to that paradise; and it has included an opening proclamation that specifies time and place: "St. David's Field, Tennessee, 1863."

So as the movie ends, viewers, having in effect been prepared for more written documentation, having played around the edges of meaning of the sub-titles, are ready enough to merge the movie's laughter and tears with the caption's advice on how to understand or read (or, now, rapidly make adjustments to -- in effect, re-read) the film, advice too on what matters in the film. Viewers may even develop strongly the feeling -- as they mentally complete the 13-year gap between picture's end and caption's observation -- that they have somehow been not only witness to, but participants in, historic events of 1863 . But they have been participants cast in the image of Lt. Dunbar, and so their distance from the gravely solemn notice seems to have been carefully pre-determined, precisely adjusted, discreetly controlled. In fact, the sweep of the grimly sobering statement -- that thirteen years later the Sioux, having been betrayed, having lost their buffalo altogether, were completely routed, presumably by the sort of white people (treacherous, crude, uncivilized) we meet in some of the opening but especially in the closing episodes of the movie and to whose "white authority . . . the last band of free Sioux submitted" -- seems not to apply to the viewer at all.

So the closing caption, the authenticating mechanism with which Dances With Wolves concludes, gives the appearance of strongly enforcing, intellectually endorsing, a reading of history ascribing to white society a verdict of guilty; but it is a white society only vaguely posited in terms of associations with any real white movie audience, and surely not a white society any individual viewer who has been compelled by all available conventions to identify with the film's white hero, Lt. Dunbar, would tolerate. Thus, that dangling caption, although it posits the white man's culpability in the demise of the Lakota Sioux, and so provides the film-viewer with the sense that a culprit rightly has been identified, certainly does not indict any particular member of the audience. Though it seems conclusive and enclosing, the caption has little effect in usurping the more conservative drive of the film. If offers the comfort of politically correct posturing without challenging the greater comforts deriving from the audience member's intense personal identification with Lt. Dunbar. The caption, then, however dogmatically it seems to operate, is more re-assuring than troubling, for it barely adjusts the categories of an audience's uncritical sensibility and self-identity. It allows the audience to remain distant from atrocities past or present.

As an invitation to an essentially new narrative, a new story not dominated by Dunbar/Costner, the closing caption of Dances With Wolves can intellectually be grasped readily enough, but the gap it opens up between the two oppositional narratives can be dismissed emotionally as not belonging at all to Dunbar/Costner's story; hence not to our story. Indeed, Dunbar and his transparently personal written reflections seem to be swept into a kind of safety distinct from the voice and the tone, the authoritative historicity and moral dogmatism, of the caption, just as the unfettered orality of the Lakota Sioux voice is ultimately distinct from 
the written sub-titles of the film. By letting Lt. Dunbar disappear well before the arrival of the caption into the seclusion, the closure, of his own happy ending as the camera "slowly pulls back," the pleasurable escapism of this fictional epic is assured, with only a slightly bothersome hint of subversiveness in the closing memo.

(An earlier version of this paper appears in proceedings of the April 1992 Kent State University conference on filmic identity.)

\section{Notes}

1. The wording of the closing caption appears neither in Michael Blake's 1988 novel, Dances With Wolves (we have used the Fawcett Gold Medal fifth printing text, New York, 1990), nor in Kevin Costner, Michael Blake, Jim Wilson, and (photographer) Ben Glass's two publications, Dances With Wolves: The Illustrated Story of the Epic Film, edited by Diana Ladau (New York: Newmarket Press, 1990) and Dances With Wolves: The Illustrated Screenplay and Story Behind the Film, abridged edition (New York: Newmarket Press, 1991); the references we have made to the closing shots come from the two latter works. We are grateful to Don LePan at Broadview Press (Peterborough, Ontario) for his help; The Broadview Reader (second edition), edited by Herbert Rosengarten and Jane Flick, contains important alternate interpretations of Dances With Wolves. Our thanks, also, to Gerald Noonan, Wilfrid Laurier University, for his comments. We presented this paper at the "Reflecting on 1492: Past and Present" Interdisciplinary Conference held at Wilfrid Laurier University, November 1992. 2. Megan Stern finds in films such as Dances With Wolves "fantasies of remasculinization rather than portrayals of the American frontier from a Native-American perspective. . . . Indeed, their sympathetic attitude toward Indian culture itself emerges as a necessary element in the retrieval of contemporary, American masculinity." See Stern's insightful essay, "Making the Old Myth New: The Frontier in The Last of the Mohicans and Dances With Wolves," in Wasafiri, 17 (Spring 1993): 49-53. 